\title{
An Alternative Femoral Stem-bone Implantation Technique Using an Innovative Short Femoral Stem Endoprosthesis
}

\author{
MARIUS MOGA², AUGUSTIN SEMENESCU², RAZVAN DANIEL CHIVU³, MIHNEA COSMIN COSTOIU², ILEANA MARIANA MATES ${ }^{1}$, \\ CEZAR IONUT CALIN ${ }^{1}$, CATALIN GHEORGHE AMZA², MARK EDWARD POGARASTEANU1*, ANA MARIA OPROIU3*, \\ FLORENTINA IONITA RADU ${ }^{1}$ \\ ${ }^{1}$ Central Universitary Emergency Military Hospital Dr. Carol Davila, 134 Calea Plevnei, 010825, Bucharest, Romania, \\ 2 Politehnica University Bucharest, 313 Splaiul Independentei 060042, Bucharest, Romania \\ ${ }^{3}$ Carol Davila University of Medicine and Pharmacy Bucharest, 3-7 Dionisie Lupu Str., 020022, Bucharest, Romania
}

\begin{abstract}
Arthroplasty of the hip, for either arthritic changes or femoral neck fracture, is a common procedure in orthopedic surgery. Although the standard designs for implantation, either cemented or uncemented, are well described and studied, there are also alternative designs regarding the implantation of both prosthetic stem and cup. This paper aims to explore one such alternative design, using the screw-in technique. It has been described in past literature for uncemented fixation of both the cup and the stem, and the biomechanical principles of fixation are different from the classical methods, offering certain advantages that are insufficiently explored in current-day endoprosthesis. Also, we will be presenting an innovative femoral stem design, recently developed, that combines an uncemented screw-on technique with a cemented augmentation possibility, aimed to provide the practitioner with the advantages of a bone-preserving mini-stem design, combined with the innovative screw-in fixation technique and the versatility of the hybrid cemented/ uncemented fixation method.
\end{abstract}

Keywords: Hip, arthroplasty, short stem

Arthroplasty of the hip, for arthrosis, femoral neck fracture or femoral head avascular necrosis is a common procedure in orthopedic surgery [1].There are current-day time-tested and widely used prosthesis designs, uncemented for younger patients, with a better bone stock, and cemented, for elderly patients or for patients with a lower density of bone stock, but these are not the only designs for hip arthroplasty [2-4]. We aim to describe an alternative design in hip prosthesis, with a modification in the method of implantation of the femoral stem. Generally, femoral stems are impacted or cemented into the proximal femur, be it femoral neck, femoral metaphysis or metaphyso-diaphysar portion of the femur; the prosthesis design that we are presenting is a threaded primarily uncemented cervical implant, that is inserted using a screw-like motion and can be supplemented with bone cement if needed, in order to combine the advantages of the bone-preserving mini-stems with the superior stability of the cemented technique in osteoporotic bone. Thus, the presented femoral stem becomes an innovative and versatile hybrid threaded stem. Threaded fixation is a described method of uncemented fixation in both acetabular cups and femoral stems, and has been described in pastliterature [5-9].The underlying principles of fixation in the presented prosthesis differ from press-fit prosthesis or cemented prosthesis, and they offer a number of advantages that this paper aims to present.

In the 1970's, G. Bousquet developed a cementless femoral stem, coated in aluminium oxide, that would be screwed in the proximal femur and would allow for a precise control of femoral neck rotation $[10,11]$.

Following that, in the 1980's, another uncemented screw shape femoral stem was being developed in France, named the $B L$, that had metaphyseal bearing [8].

In the early 1990's, a titanium alloy revision femoral stem was developed, with a modular design, that would have the distal component implanted in a screw-in fashon; this implant was named the $B L R$, and it allowed for an independent adjustement of the anteversion. It came in three sizes, 220, 260 and $300 \mathrm{~mm}$, and 6 diameters, from 13 to $18 \mathrm{~mm}$. The proximal, metaphyseal component was coated with microspheres and used for reconstruction of bone defects with allografts $[9,12]$.

Also, in the last decades there has been a significant development in translating the concept of bone capital preservation from an orthopedic ideal to a current arthroplastic practice, through the use of small stem (mini stem) proximal femoral endoprosthesis (i.e. Primoris by Biomet, Silent Stem by DePuy, TSI Neck Plug CDD, LLC, Spiron). These cervical short stem femoral prosthesis have had a rapid evolution and are being developed in an increasingly diverse manner.

Harpal Khanuja et al. have classified the short femoral stems in 4 types [13]:

Type 1: strictly cervical stems: 1A (trapezoid), 1B (cylindrical) and $1 \mathrm{C}$ (threaded).

Type 2: with calcar loading: 2A (trapezoid), 2B (cylindrical curved), 2C (threaded) and 2D (laterally fixed with a plate and screw).

Type 3: lateral flare calcar loading.

Type 4: the microstems, with a partially covered metaphysis portion.

Type 1 stems are impacted in the femoral neck area; although they may reach the trochanteric region, they do not take purchase on the lateral cortical. They are mainly stabilized by compressing the cancellous bone and may presenta proximal collar thathas a role in force distribution, and their shape may be rectangular, cylindrical or threaded. The BHR (Birmingham Hip Resurfacing System) and the BMHR (Birmingham Mid Head Resection System), both from Smith\&Nephew, are classic examples. The BHR is a resurfacing system, while the BMHR is a cervico-cephalic prosthesis; other resurfacing systems include Adept (MatOrtho), Conserve Plus (Wright Medical Technology), Durom hip resurfacing system (Zimmer), and ReCap ${ }^{\circledR}$ 
Femoral Resurfacing System (Biomet), among many others.

The BHR [14] is a hip resurfacing system that preserves maximal bone stock in the proximal femur and may be implanted through minimally invasive techniques, thus being indicated for use in younger patients. This system requires detailed preoperative planning in order to position correctly the femoral component, and it has the advantage of preserving the natural femoral neck length and anteversion, thus greatly diminishing the risk of dislocation.

The BMHR (Birmingham Mid Head Resection) $[15,16]$ is a short cervico-cephalic femoral stem prosthesis that includes a spherical metallic femoral head that articulates with the acetabular area, and a truncated piece, with longitudinal grooves, to enhance stability, that is inserted in the remaining half of the femoral head, and in the femoral neck, with the resection level at the middle of the femoral head. This prosthesis aims to preserve as much cervical bone as possible, including a portion of the femoral head.

The Spiron, developed by Birkenhauer and presented in 2004 , is an uncemented cervical short stem prosthesis that has deep grooves and a threaded fixation, and has promising early results $[17,18]$.

Type 2 stems extend to the metaphysio-diaphyseal area and relay forces to the calcar and the lateral cortical; maximum resistance is achieved when over $50 \%$ of the femoral neck is preserved, although the aim is to preserve as close to $100 \%$ of the femoral neck as possible. Examples include Nanos (Smith\&Nephew), Metha (Aesculap-Braun) and C.F.P. ${ }^{\circledR}$ Hip Prosthesis System (Lynk).

The Nanos [19] is an excellent example, as it has both metaphyseal anchorage and load distribution, while requiring minimal bone resection. The femoral head is resected subcapitally, and the implantation technique requires a progressive use of dedicated rasps with the aim of compacting the cancellous bone in areas of maximum load, such as the Merkel spur and the lateral cortice.

Type 3 stems extend only to the metaphysis, and by compacting the cancellous bone in this area they achieve a transmission of forces closer to that seen in an unoperated proximal femur.

Proxima from DePuy [20] (fig. 1) is an excellent example of a stem from this class. This implant requires a horizontal resection of the femoral neck (fig. 2), starting from a subcapital inferior level and finishing distally at the superior base of the femoral neck, conserving $50-70 \%$ of it, and also its anteversion. It can be implanted through minimally invasive techniques, it requires detailed pre-op planning and intra-op radiologic control.

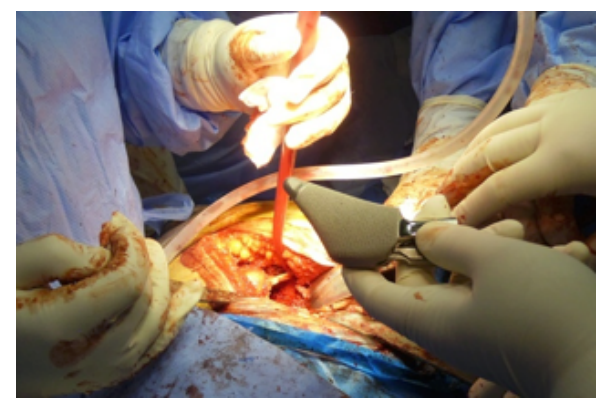

Fig. 1. A Type 3 stem-Proxima from DePuyintraoperative image. This image is from the authors' personal database

Type 4 are conventional shortstems, covered in a porous material in the metaphyseal area, with a reduced distal stress on the prosthesis' end. The femoral resection is executed at the same level as in a standard uncemented prosthesis and the bone stock conservation in the trochanteric and cervico-cephalic area is achieved through the stem's design. Examples include Tri-Lock (De-Puy

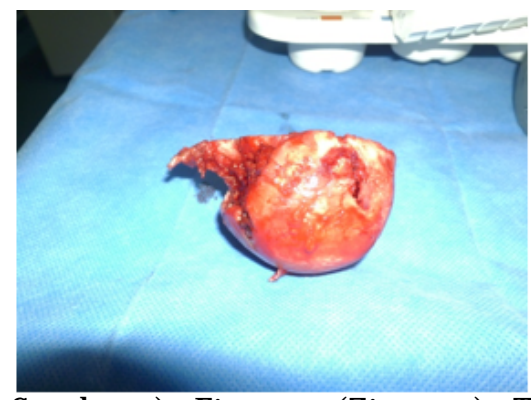

Fig. 2. Resection level of the femoral neck in a Proxima Prosthesis.

This image is from the authors' personal database

Synthese), Fitmore (Zimmer), Taperloc Microplasty (Biomet) and SMF hip system (Smith\&Nephew).

Taperloc Microplasty [21] (fig. 3) is a good example of a stem from this class; it is based on Biomet's flat tapered wedge design philosophy, and can be implanted through minimally invasive techniques.

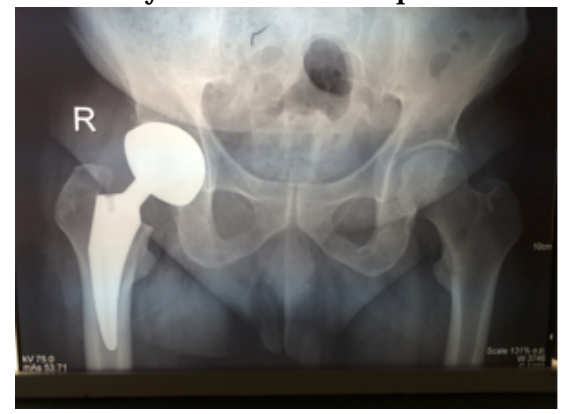

Fig. 3. Post-op radiographic image of an implanted Taperloc Microplasty stem. This image is from the authors' personal database

The objective of this paper is to present an innovative femoral stem component for a hip endoprosthesis, which offers an alternative for the treatment of aseptic femoral head necrosis or femoral neck fracture, in younger patients.

\section{Experimental part}

\section{Materials and methods}

Aiming to open a new avenue of development in hip arthroplasty, we developed a short femoral stem cervical endoprosthesis (fig. 4), with an indication of use in total hip arthroplasty for hip arthrosis and femoral head avascular necrosis, in a young patient.

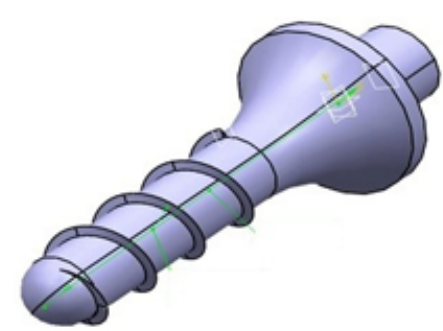

Fig. 4. Computer rendering of the short stem femoral endoprosthesis. This image is from the authors' personal database [22]

In all hip arthroplasty cases, but more so in the young patients, it is very important to preserve as much femoral bone stock as possible, given that an endoprosthesis has a limited period of usage before it has to be revised and replaced; the revision surgery becomes ever more difficult each time, so it stands to reason that a femoral implant must aim to preserve as much bone as possible with each surgery.

Keeping in mind that a total hip arthroplasty involves the replacement of the deteriorated femoral head and acetabulum with an artificial head (either metallic or ceramic), an acetabular cup (either metallic or ceramic) and an insert in the case of uncemented cups, we must mention that an area of interest in modern hip arthroplasty is the preservation of femoral bone stock, especially around the neck area, a problem adressed by the short stem endoprosthesis and by the femoral head resurfacing implants.

The insertion of the femoral stem is done withoutpressfitting, using a motion similar to the insertion of a screw, 
Table 1

MECHANICAL PROPRIETIES OF CORTICAL HUMAN BONE, TITANIUM AND TITANIUM ALLOY (ADAPTED FROM [24-28])

\begin{tabular}{|l|l|l|l|}
\hline Material & $\begin{array}{l}\text { Cortical } \\
\text { bone }\end{array}$ & Titanium & $\begin{array}{l}\text { Titanium } \\
\text { alloys }\end{array}$ \\
\hline Young's Modulus (GPa) & $0-30$ & $110-117$ & 110 \\
\hline Resistance to traction (MPa) & $50-150$ & $240-345$ & 760 \\
\hline Resistance to compression (MPa) & $130-180$ & $758-1117$ & $848-1080$ \\
\hline Density (g/cm3) & $1.8-2.1$ & $4.4-4.5$ & 4.5 \\
\hline
\end{tabular}

thus theoretically diminishing considerably the risk of femoral neck fracture.

This type of innovative femoral stem allows for the retention of maximum bone stock in the femoral neck, while preserving natural biomechanics in the hip joint, and allowing for an easier revision surgery later in life, if needed. The preservation of natural anatomy and biomechanics is accomplished by resecting the femoral head at the cervicocephalic jonction.

The proposed implant materials are Ti6AI4V titanium alloy and titanium, which are biocompatible and provide adequate mechanical proprieties to the prosthesis [23]. When comparing the mechanical proprieties of human bone (cortical bone) with the mechanical proprieties of metals (titanium and Ti6Al4V titanium alloy), as seen in table 1, we see that titanium and titanium alloy closely match cortical bone regarding Young's Modulus and resistance to bending/fracture.

As can be seen in table 1, human bone resembles titanium and titanium alloys when mechanical proprieties are concerned (i.e. resistance to traction, Young's Modulus and density). Using titanium alloys (Ti6AI4V) as a base for manufacturing the threaded short stem cervical prosthesis would ensure a better mechanical integration of the prosthesis in the surrounding bone, with a transmission of forces closer to that which would occur naturally.

The body on the endoprosthesis will be covered in a biocompatible material, hidroxyapatite HA [Ca10(P04)6(OH)2], which is derived from calcium phosphate, and has a structure verymuch like the inorganic phase of human bone, being bioactive, biocompatible and osteoconductive and osteoinductive, with no local toxic effects. HA also has a slow rate of degradation. The disadvantage in using HA to coat endoprosthesis is it's mechanical fragility, with a fast rate of fissure formation under mechanical stress. The method by which the endoprosthesis' threaded stem will be covered in HA is conversion, by immersion in a simulated biological fluid (SBF), which at $37^{\circ} \mathrm{C}$ and $7.4 \mathrm{pH}$ is a biomimetic process [29].

The presented cervical short femoral stem prosthesis replaces only the femoral head, affected by arthritic degeneration or by aseptic femoral head necrosis, thus maintaining a natural hip joint anatomy and preserving femoral bone stock. The natural anatomy of each individual patient is preserved by maintaining the length anteversion of the femoral neck, therefore eliminating a potential cause of dislocation in the future, and recreating a biomechanical scenario as close to the original setting as possible. The bone stock that is preserved is the cortical and cancellous bone in the femoral neck, as well as the majority of the cancellous bone in the proximal femoral metaphysis.

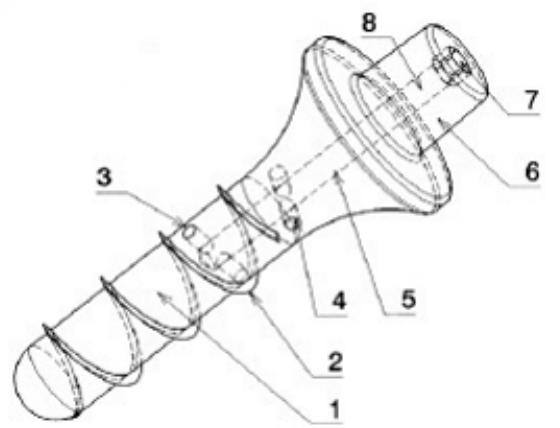

Fig. 5. Schematics of the short stem femoral endoprosthesis: 1 -body; 2 -helical coil; 3,4 -transversal openings; 5 -truncated sleeve; 6 -neck; 7 -hexagonal opening; cylindrical opening. This image is from the authors' personal database [30]

The endoprosthesis (fig. 5) [31] has a body that is cylindrical in shape, with a slightly elongated tip, in order to match as closely as possible the anatomic shape of the femoral neck, while at the same time allowing for a threading motion to be applied while inserting the prosthetic femoral stem, which progressively compacts the cancellous bone in the femoral neck and ensures a firm fixation; it can be forged out of a titanium based alloy, and that will be covered in hidroxyapatite. On the body there is a helical coil, that is followed by a truncated sleeve and then by the neck of the prosthesis. The helical coil allows for improved stability of the prosthesis in the compacted cancellous bone, ensuring a larger area of contact between prosthesis and bone and acting as a multiplane anti-displacement device. The truncated sleeve acts as a secondary stabilizer, through its shape, also playing a role in force distribution, while the neck of the prosthesis serves as a base on which the femoral head will be impacted. The neck of the prosthesis has an internal hexagonal opening that is continued with a cylindrical opening, running half the length of the prosthesis, that has two transversal openings. The hexagonal opening allows for the insertion of a torque screwdriver, in order to introduce and secure the prosthesis in place, and after the removal of the screwdriver, low viscosity orthopedic cement (PMMA) may be inserted through the cylindrical opening with a syringe. The cement exits through the transversal openings, set in perpendicular planes one to the other, helping to augment the prosthesis' fixation in the femoral neck, if considered necessary. The use of this supplementary cement fixation is optional, and it provides the surgeon with an extra method of fixation, in case the bone quality of the femoral neck is less than optimal, and the surgeon feels that a better fixation is required, until the hidroxyapatite is fully bonded to the bone.

The cementing comes as an augmentation to the process of threading through which the prosthesis is inserted, a process that improves osseointegration through an increased application force at the interface between bone and prosthesis.

\section{Results and discussions}

The aim of the prosthesis (fig. 6) is the preservation of as much bone capital as possible, thus conserving normal hip joint anatomy and biomechanics. The prosthesis is affixed to the cervical bone through press-fitting, with a threading-type method of insertion of the femoral stem into the cervical cancellous bone, withouthammering and without exerting significant axial compression, assuring primary fixation. The proximal femoral stem is covered in an osseointegrating biomaterial, such as hydroxiapatite, thus assuring the secondary fixation of the endoprosthesis. 


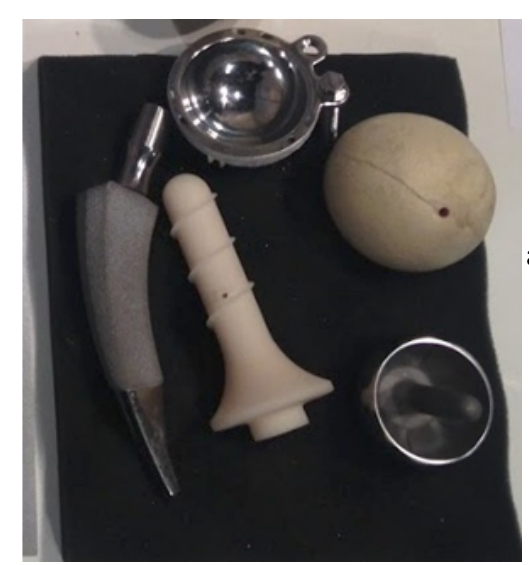

Fig. 6. The short stem femoral endoprosthesis (center) shown with an acetabular cup, a resected bone model femoral head, a short femoral stem and the BMHR. This image is from the author's personal database

The two fixation methods (primary and secondary) can be augmented through a tertiary fixation, the introducing of orthopedic cement throughout the prosthesis via the channel system, thus improving axial stability and final long-term fixation.

The surgical technique through the endoprosthesis is implanted has several modified key steps:

The hip is addressed through a mini invasive approach, the femoral head is dislocated and a subcapital osteotomy is performed (fig. 7), thus eliminating the damaged femoral head [31].

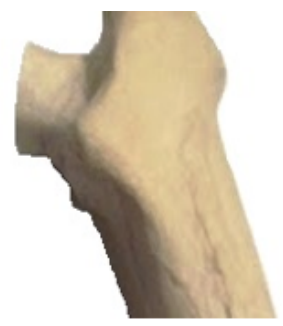

Fig. 7. Femoral neck resection level on a bone model. This image is from the authors' personal database

After measuring the diameters of the femoral neck on the osteotomy section, the center of the neck is determined and marked; through this point a metal guide pin is introduced and a tunnel is then drilled right up until the lateral cortical bone. The diameter of the tunnel is calculated using the measured femoral neck diameters [31].

The trabecular bone in the femoral neck and trochanteric area tunnel is compacted using a dilator in order to provide better support for the threading of the prosthesis [31].

The size of the prosthesis is determined based on the length of the drilled tunnel and on the diameter of the same tunnel. The prosthesis is threaded into place using a torque screwdriver.

Orthopedic cement (PMMA) may be inserted through the main opening (numbers 7 and 8 in fig. 5), leaving the canals through the transversal orifices 3 and 4 and securing the prosthesis into place by interconnecting with the adjacent bone alveoli.

The head of the prosthesis is press-fitted and the rest of the procedure is done according to the preferred surgical technique.

Although short femoral stem prosthesis have known a recent period of developement internationally, locally, in Romania, little research has been done on the subject, comparative to, for example, the area regarding exoprosthesis [32-35], and so the conception of this innovative femoral stem through collaboration between the medical field and engineering opens new avenues for inquiry and exploration.

\section{Conclusions}

The advantages offered by the use of the short stem threaded cervical prosthesis are a more stabile fixation, through the use of the hybrid uncemented - cemented technique and an easier implantation promising a shorter surgery time, with an accelerated rehabilitation, while preserving a maximum of bone stock in the femoral neck and trochanteric area, vital to increasing the potential for an easier revision surgery.

The use of minimal invasive surgical approaches allows for an early mobilisation of the patient, and a faster return to an active life.

Acknowledgements: The authors would like to thank the Military Hospital's staff for the support in writing this article.

\section{References}

1. BAHL J.S., NELSON M.J ., TAYLOR M., SOLOMON L.B., ARNOLD J.B., THEWLISD., Biomechanical changes and recovery of gait function after total hip arthroplasty for osteoarthritis: a systematic review and meta-analysis, Osteoarthritis Cartilage, 2018, pii: S1063-4584(18)310136

2. ZAGRA L., Advances in hip arthroplasty surgery: what is justified?, EFORT Open Rev., 2(5), 2017, P. 171-78.

3. ENOKSEN C.H., WIK T.S., KLAKSVIK J ., ARTHURSSON A.J ., HUSBY O.S., GJ ERDET N.R., Load transfer in the proximal femur and primary stability of a cemented and uncemented femoral stem: An experimental study on cadaver femurs, Proc Inst Mech Eng $\mathrm{H}$., 231(12), 2017,p. 1195-1203.

4. ORBAN H., ADAM R., ORBAN C., Arthroplasty risk after liver or kidney transplant, Revista Societatii Romane de Chirurgie, 5(107), 2012, p. 664-69.

5. VOGEL D., RATHAY A., TEUFEL S., ELLENRIEDER M., ZIETZ C., SANDER M., BADER R., Experimental analysis of insertion torques and forces of threaded and press-fit acetabular cups by means of ex vivo and in vivo measurements, Acta Bioeng Biomech., 19(3), 2017, p. $155-63$.

6. SCHMOLDERS I., AMVRAZIS G., PENNEKAMP P.H., STRAUSS A.C., FRIEDRICH M.J ., WIMMER M.D., ROMMELSPACHER Y., WIRTZ D.C., WALLNY T., Thirteen year follow-up of a cementless femoral stem and a threaded acetabular cup in patients younger than fifty years of age., Int Orthop., 41(1), 2017, p. 39-45.

7. ELLENRIEDER M., BADER R., BERGSCHMIDT P., MITTELMEIER W., Press-fit versus threaded acetabular cups in total hip arthroplasty: Functional and radiological results after five years, Acta Orthop Belg., 82(1), 2016, p. 60-7.

8. LECESTRE P., BEDOUCHA J.S., Premiers résultats de la prothèse fémorale vissée sans ciment "BL", Rev Chir Orthop, 75(1), 1989, p. $121-2$.

9. LECESTRE P., DELPLACE J., POILBOUT PH., MIGEON A., Presentation de la prothese femorale sans ciment de reconstruction BLR - Resultats preliminaires, La Rochelle Cedex: Orthop Traumatol., 3, 1993, P. 22733.

10. BOUSQUET G., ARGENSON C., GODENECHE J. L., CISTERNE J .P, GAZIELLY D.F., GIRARDIN P., DEBIESSE J.L., Reprises apres descellement aseptique des arthroplasties totales de hanche cimentées par la prothèse sans ciment de Bousquet: à propos de 136 observations, Revue de Chirurgie Orthopédique et Réparatrice de L'appareil Moteur, 72(2), 1986, P. 70-4.

11. KEPPLER L., MCTIGHE T., The Role of Stem Modularity for THA in a Community Based Practice, JISRF Reconstructive Review, 2(1), 2012, P. 16-27.

12. BOUSQUET G., RAMBERT A., Tige intramedullaire pour prothèse vissee, Patent EP 0399920 Al, 1990.

13. KHANUJA H., BANERJEE S., JAIN D., PIVEC R., MONT M., Short bone-conserving stems in cementless hip arthroplasty, J Bone Joint Surg Am., 96(20), 2014, P 1742-52. 
14.FORREST N., WELCH A., MURRAY A.D., SCHWEIGER L., HUTCHISON J., ASHCROFT G.P., Femoral head viability after Birmingham resurfacing hip arthroplasty: assessment with use of [18F] fluoride positron emission tomography, J Bone Joint Surg Am., 88(3), 2006, p. 84-9.

15. ITAYEM R., ARNDT A., DANIEL J., MCMINN D.J ., LUNDBERG A., A two-year radiostereometric follow-up of the first generation Birmingham mid head resection arthroplasty, Hip Int., 24(4), 2014, P. 355-62.

16. RAHMAN L., MUIRHEAD-ALLWOOD S.K., The Birmingham midhead resection arthroplasty-minimum two year clinical and radiological follow-up: an independent single surgeon series, Hip Int., 21(3), 2011, P. 356-60

17. BIRKENHAUER B., KISTMACHER H., RIES J ., Conception and first results of the Spiron cementless femoral neck screw prosthesis, Orthopade., 33(11), 2004, p. 1259-66.

18. LUGEDER A., HARING E., MULLER A., DROSTE P., ZEICHEN J ., Total hip arthroplasty with the cementless spiron femoral neck prosthesis, Oper Orthop Traumatol., 25(4), 2013, p. 388-97.

19. ETTINGER M., ETTINGER P., LERCH M., RADTKE K., BUDDE S., EZECHIELI M., BECHER C., THOREY F., The NANOS short stem in total hip arthroplasty: a mid term follow-up, Hip Int., 21(5), 2011, p. 583-6.

20. GHERA S., PAVAN L., The DePuy Proxima hip: a short stem for total hip arthroplasty. Early experience and technical considerations, Hip Int., 19(3), 2009, P. 215-20.

21. LABEK G., FRISCHHUT S., SCHLICHTHERLE R., WILLIAMS A., THALER M., Outcome of the cementless Taperloc stem: a comprehensive literature review including arthroplasty register data, Acta Orthop., 82(2), 2011, p. 143-8.

22. MOGA M., BARBILIAN A., Considerations in the minimally invasive short stem arthroplasty of the hip, Globe Edit, 2017, ISBN: 978-620-248736-8, P. 51.

23. DANTAS T.A., ABREU C.S., COSTA M.M., MIRANDA G., SILVA F.S., DOURADO N., GOMESJ .R., Bioactive materials driven primary stability on titanium biocomposites, Mater Sci Eng C Mater Biol Appl., 77, 2017, p. 1104-10.

24. YUAN H., DE GROOT K., Calcium Phosphate Biomaterials: An Overview, NATO Science Series II: Mathematics, Physics and Chemistry, 171, 2005, p. 37-57.
25.STAIGER M.P., PIETAK A.M., HUADMAI J., DIAS G., Magnesium and its alloys as orthopedic biomaterials: a review, Biomaterials, 27, 2006, P. 1728-34.

26. NARAYANAN S., PARK I.S., LEE M.H., Surface Modification of Magnesium and its Alloys for Biomedical Applications: Biological Interactions, Mechanical Properties and Testing, Elsevier, 2015. P. 160-5, 281-3; 222-39, 288-95.

27.*** SPECIAL METALS AND PRODUCTS S.L., TITANIUM. HTTPS:// SMP.ES/EN/TITANIUM, 01.05.2018.

28.***AZOM, Titanium Alloys - Ti6Al4V Grade 5, https://www.azom.com/ properties.aspx?ArticlelD=1547, 01.05.2018.

29. MULLER L., MÜLLER F.A., Preparation of SBF with different $\mathrm{HCO} 3$ content and its influence on the composition of biomimetic apatites, Acta Biomater, 2, 2006, p. 181-9.

30.*** (OSIM), THE STATE OFFICE FOR INVENTIONS AND TRADEMARKS, The Official Industrial Propriety Bulletin - Section: Patent, Editura OSIM, 2015, p. 2065-2100.

31. MOGA M., SEMENESCU A., COSTOIU M.C., MATE' I.M., CALIN C.I., AMZA C.G., Endoproteza Scurta Cervicala Femurala - Short Femoral Cervical Endoprosthesis, A00155 OSIM Romania - The State Office for Inventions and Trademarks, 2015.

32. OSICEANU S., DASCALU M., BARBILIAN A., Intelligent interfaces for locomotory prosthesis - 2009 International Joint Conference on Neural Networks, International J oint Conference on Neural Netw orks IEEE, 978-1-4244-3548-7, 2009.

33. FRANTI E., MILEA L., BARBILIAN A., BUTU V., CISMAS S., LUNGU M., SCHIOPU S., Methods of acquisition and signal processing for myoelectric control of artificial arms, ROMJIST, 15(2), 2012, p. 91105.

34.P.L. MILEA, Monica DASCALU, C.O. OPRIS, Eduard FRANTI, M. DUMITRACHE, and Cristian Ioan STOICA, Using pressure sensors for motion detection and actuation of remote manipulation, Romanian Journal of Information Science and Technology, Volume 19, Number 4, 2016, 321-330

35.P.L.MILEA, DASCALU, M., FRANTI, E., BARBILIAN, A., STOICA, I.C.,Tactile Feedback Experiments for Forearm Prosthesis with Myoelectric Control, ROMANIAN J OURNAL OF INFORMATION SCIENCE AND TECHNOLOGY Volume20, Number 2, 2017, 101-114

Manuscript received: 20.08 .2018 